\title{
Microspatial Distributional Patterns of Vectors of Cutaneous Leishmaniasis in Pernambuco, Northeastern Brazil
}

\author{
Maria Rita Donalisio, ${ }^{1}$ A. Townsend Peterson, ${ }^{2}$ Pietra Lemos Costa, ${ }^{3}$ \\ Fernando José da Silva, ${ }^{3}$ Hélio França Valença, ${ }^{3}$ Jeffrey J. Shaw, ${ }^{4}$ and Sinval P. Brandão Filho ${ }^{3}$ \\ ${ }^{1}$ Departmento de Medicina Preventiva e Social, Faculdade de Ciências Médicas, UNICAMP, Rua Tessalia Vieira de Camargo 126, \\ 13083-887, Campinas, São Paulo, Brazil \\ ${ }^{2}$ Biodiversity Institute, University of Kansas, 1345 Jayhawk Boulevard, Lawrence, 66045, USA \\ ${ }^{3}$ Instituto Aggeu Magalhães, Fundação Oswaldo Cruz, Avenida Moraes Rego s/n, 50670-420 Recife, PE, Brazil \\ ${ }^{4}$ Instituto de Ciências Biomédicas, Universidade de São Paulo, Avenida Prof. Lineu Prestes 2415, 05508-900 São Paulo, SP, Brazil
}

Correspondence should be addressed to Maria Rita Donalisio, rita.donalisio@gmail.com

Received 16 August 2011; Accepted 9 October 2011

Academic Editor: Elizabeth F. Rangel

Copyright (C) 2012 Maria Rita Donalisio et al. This is an open access article distributed under the Creative Commons Attribution License, which permits unrestricted use, distribution, and reproduction in any medium, provided the original work is properly cited.

\begin{abstract}
The purpose of this study is to analyze the spatial distribution and population trends through time of Lutzomyia species in a long-term focus of cutaneous leishmaniasis transmission in an Atlantic Forest area, northeastern Brazil. Sand fly populations of different ecological niches were monitored spatiotemporally in 2009. To summarize vegetation characteristics and phenology, we calculated the Normalized Difference Vegetation Index from Landsat images. Using niche modeling approaches, we assessed suites of environmental factors to identify areas of transmission risk. Although 12 species were detected, L. whitmani was the most abundant and broadly distributed across the area, particularly in peridomiciliary locations, and associated negatively with denser vegetation areas. On the other hand, L. complexa, L. sordelli, and L. tupynambai were found almost exclusively in forested areas $(P<0.05)$, and associated positively with denser vegetation. Lutzomyia species' occurrences are related to specific environmental combinations (with contrast among species) in the region.
\end{abstract}

\section{Introduction}

American Cutaneus Leishmaniasis (ACL) is a vector-borne zoonotic disease caused by several species of Leishmania trypanosome protozoan parasites and transmitted by phlebotomine sandflies (Lutzomyia spp.). In Brazil, ACL constitutes a significant health problem, with an incidence of about 20,153 new cases per year (2008) [1]. In humans, infections may not be readily apparent but can present a variety of clinical manifestations ranging from localised, sometimes selfhealing cutaneous lesions to severe mutilating mucocutaneous lesions or diffuse cutaneous leishmaniasis [2]. A high prevalence of infection has been reported in Pernambuco state, northeastern Brazil, concentrated predominantly in the Atlantic Forest region; transmission has increased dramatically in recent decades $[3,4]$.

Many different patterns of ACL etiology have been described in Brazil, particularly in highly endemic regions [5].
ACL was originally considered to be focused among people who work or live within tropical forests; however, comparison of this idea with current patterns of occurrence suggests strongly that behavior of vectors may be changing, perhaps in response to environmental shifts $[1,6,7]$. Numerous studies point to the capacity of some Lutzomyia species to adapt to human-altered environments in parts of Brazil $[1,8-10]$, which opens possibilities for broader and much increased transmission.

The sandflies Lutzomyia whitmani and L. migonei are considered important ACL vectors in Brazil that have generally been found in peridomestic environments in southeastern (states of São Paulo, Minas Gerais, Espírito Santo, Rio de Janeiro) [11-13], northeastern (Maranhão, Bahia, Ceará, Pernambuco) [14-16], and west-central (Mato Grosso, Mato Grosso do Sul, Tocantins) regions [10, 17-19]. Lutzomyia intermedia, on the other hand, dominates and is considered 


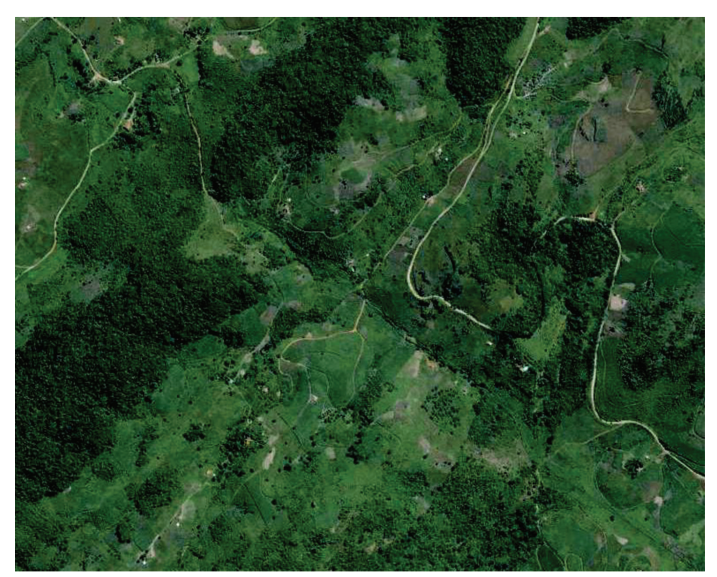

Figure 1: The Amarají landscape Pernambuco, Brazil, 2009, scale = $1: 24,000$.

the principal ACL vector in areas of São Paulo, Rio de Janeiro, and Minas Gerais $[1,11,12]$. Various factors have been identified as key in this domiciliation process, including climatic factors (annual and seasonal temperature and precipitation), vegetation type, and elevation, as well as socioeconomic conditions that may influence risk of transmission to humans $[20,21]$. Finally, Lutzomyia whitmani ranks among the most important ACL vectors in Brazil [22] and has been found to be abundant in Atlantic Forest areas in Pernambuco since at least the 1990s [4, 16]. This species has been found to be infected naturally with Leishmania (Viannia) braziliensis in this region, forming a key element in the zoonotic transmission cycle of this pathogen $[23,24]$.

The purpose of this study is to analyze the "behavior" in terms of distribution and population trends through time and across space of Lutzomyia species in a long-term focus of ACL transmission in the state of Pernambuco, Brazil. Given that L. whitmani dominates the sandfly fauna in this region almost absolutely [16], we focus on this species, as it clearly drives much of the dynamics of the system. We explore this species in relation to various environmental factors in Amarají, Pernambuco, an area of intermingled Atlantic Forest and farmland that is of particular interest as regards high ACL transmission [3, 24].

\section{Methods}

During the course of 2009, sandflies were collected in the municipality of Amarají, an Atlantic Forest-dominated locality just inland from the coast of Pernambuco. Specifically, we collected at the small, rural settlements of Refrigerio and Tranquilidade $\left(8^{\circ} 22^{\prime} 59^{\prime \prime} \mathrm{S} 35^{\circ} 27^{\prime} 09^{\prime \prime} \mathrm{W}, 289 \mathrm{~m}\right.$; Figure 1). The sampling covered 9 months of 2009 (January, February, March, April, June, August, October, November). We used 10 CDC light traps [25] per night on 3-4 nights, for a total of 255 trap-nights over the course of the study. The sampling squeme was habitat based-one CDC light trap inside domiciles, and four in peridomicile (including animal shelters), and five in nearby forested areas. The traps were positioned $1.5 \mathrm{~m}$ above the ground on the edges of banana plantations or Atlantic Forest fragments, in the interior of forest fragments, and around human domiciles and associated structures (stables, granaries, etc.). Each site was visited every second month, and the two sets of sites were sampled in alternating sets of months to maximize numbers of sites included in the study. An initial analysis of temporal dimensions sandfly abundance in this study has already been published [16]. The location of each trap was georeferenced using a hand-held Garmin (eTrex HC series) global positioning unit, accurate to $\sim 10 \mathrm{~m}$ on the ground using the datum WGS 1984.

The species Lutzomyia whitmani was analyzed separately from the other species occurring in the area because of its near-absolute dominance among the sandfly fauna of the region [16]. Species were identified based on morphology and recent keys [26]. We used chi-squared tests to compare relative frequencies of different species in different environments, both in terms of numbers of individuals captured and numbers of sites at which the species were collected. We compared L. whitmani with the remaining Lutzomyia species except as constrained by sample sizes for the latter species (expected frequencies had to be $\geq 5$ for tests to be possible). All statistical tests were based on an $\alpha=0.05$.

To summarize dimensions of land cover and vegetation characteristics and phenology, we calculated the Normalized Difference Vegetation Index (NDVI) from Landsat images available from the U.S. Geological Survey (http:// glovis.usgs.gov/) with spatial resolution of $30 \mathrm{~m}$ (98 ft). Specifically, we used images from the Enhanced Thematic Mapper-7 sensor for the following dates: 3 October and 21 October 2006, 15 April 2007, and 8 August 2009, which were the most cloud-free images available over the period 20062009. To calculate NDVI, we used the formula 10,000 [(B40$\mathrm{B} 30) /(\mathrm{B} 40+\mathrm{B} 30)]$, where $\mathrm{B} 40$ and $\mathrm{B} 30$ represent the red and near-infrared bands from the Landsat images, respectively.

To identify environmental conditions under which Lutzomyia species occur in the Amarají region, we used ecological niche modeling (ENM) routines implemented in Maxent [27]. In general, we used default parameters to train models, so that we set the random testing percentage to $50 \%$ to provide an independent perspective on model quality; we focused on the logistic output format. To identify environmental parameters most relevant to the species' occurrence, we used a jackknife procedure that measures effects of each environment variable alone and when omitted from the model on predictions $[27,28]$.

To separate areas predicted as suitable from those predicted as unsuitable [29], we set the expected meaningful error parameter of Peterson et al. (2008) [30] as $E=2 \%$. We used as a threshold for separating prediction of suitability from prediction of unsuitability the highest logistic Maxent suitability value that included $(100-E) \%$, in this case $98 \%$ of the training data, to take into account the possible presence of noise in the input data.

To provide a quantitative test of model predictions, we were forced to focus on a subset of the study area, for which no cloud cover was present in at least two of the images (Figure 1). To provide a clear test of predictive ability among spatial subsets, thereby avoiding some problems with spatial 
TABle 1: Frequency of positive sites and individuals of species of Lutzomyia sandflies identified in forested and peridomiciliary areas in Amarají, Permambuco, Brazil, in 2009. More than one species of Lutzomyia was found at some sites.

\begin{tabular}{|c|c|c|c|c|c|c|c|}
\hline \multirow{4}{*}{ Species } & \multirow{2}{*}{\multicolumn{2}{|c|}{$\begin{array}{l}\text { Sites }(n=255) \\
\text { Peridomicile forested }\end{array}$}} & \multirow{2}{*}{\multicolumn{4}{|c|}{$\begin{array}{c}\text { Individuals }(n=1,361) \\
\text { Peridomicile forested }\end{array}$}} & \multirow{4}{*}{$\begin{array}{l}\text { Total individuals } \\
\text { Freq (\%) }\end{array}$} \\
\hline & & & & & & & \\
\hline & $(n=130)$ & $(n=125)$ & \multirow{2}{*}{$P$} & \multirow{2}{*}{ Freq (\%) } & \multirow{2}{*}{ Freq (\%) } & \multirow{2}{*}{$P$} & \\
\hline & Freq $(\%)$ & Freq $(\%)$ & & & & & \\
\hline L. whitmani & $69(82.1)$ & $15(17.9)$ & $<0.001$ & $1135(95.0)$ & $60(5.0)$ & $<0.001$ & 1195 (87.8) \\
\hline Other species: & $44(57.9)$ & $32(42.1)$ & 0.41 & $82(49.4)$ & $84(50.6)$ & 1 & $166(12.2)$ \\
\hline L. evandroi & $22(66.7)$ & $11(33.3)$ & 0.18 & $43(64.2)$ & $24(35.8)$ & 0.10 & $67(4.9)$ \\
\hline L. quinquefer & $17(89.5)$ & $2(10.5)$ & 0.015 & $23(88.5)$ & $3(11.5)$ & 0.006 & $26(1.9)$ \\
\hline L. complexa & $1(10.0)$ & $9(90)$ & 0.07 & $1(5.6)$ & $17(94.4)$ & 0.007 & $18(1.3)$ \\
\hline L. sordelli & $0(0)$ & $8(100)$ & - & $0(0)$ & $16(100)$ & 0.005 & $16(1.2)$ \\
\hline L. tupynambai & $0(0)$ & $2(100)$ & - & $0(0)$ & $15(100)$ & 0.006 & $15(1.1)$ \\
\hline L. migonei & $9(90.0)$ & $1(10)$ & - & $10(90.9)$ & $1(9.1)$ & 0.06 & $11(0.8)$ \\
\hline L. fischeri & $2(66.7)$ & $1(33.3)$ & - & $2(66.7)$ & $1(33.3)$ & - & $3(0.2)$ \\
\hline L. capixaba & $1(33.3)$ & $2(66.7)$ & - & $1(33.3)$ & $2(66.7)$ & - & $3(0.2)$ \\
\hline L. walkeri & $0(0)$ & $3(100)$ & - & $0(0)$ & $3(100)$ & - & $3(0.2)$ \\
\hline L. naftalekatzi & $1(100)$ & $0(0)$ & - & $2(100)$ & $0(0)$ & - & $2(0.1)$ \\
\hline L. longispina & $0(0)$ & $2(100)$ & - & $0(0)$ & $2(100)$ & - & $2(0.1)$ \\
\hline Total negative (135) & $48(35.6)$ & $87(64.4)$ & 0.02 & & & & \\
\hline Total positive (120) & $82(68.3)$ & $38(31.7)$ & 0.005 & $1217(89.4)$ & $144(10.6)$ & $<0.001$ & $1361(100)$ \\
\hline
\end{tabular}

autocorrelation among training and testing data, we separated this subset of the study region into eastern, central, and western areas and challenged models to use each pair of areas to anticipate the distribution of the species in the third area. We then used a receiving operating characteristic (ROC) approach to provide a threshold-independent evaluation of each prediction [30]. However, in light of known problems with standard ROC approaches [31,32], we used a partial ROC approach, in which analyses are limited to portions of the ROC curve in which omission error is less than or equal to $E$; these tests were developed using a program developed by N. Barve that is available upon request from the authors. The test statistic output from these routines is the AUC ratio, which compares the observed area under the curve to null expectations; AUC ratios are tested for difference from unity (i.e., random prediction) via 1000 repetitions of a $50 \%$ bootstrap of available input data.

Finally, to provide a visualization of ecological niche patterns of Lutzomyia species' distributions in the study area, we developed a final niche model based on all occurrence data available across the three areas (i.e., no subsetting). We combined (grid COMBINE in ArcGIS 9.3) this map with the environmental data layers from which it was derived to yield a raster dataset with an associated attributes table that includes the value of each combination of environmental variables (NDVI of each time period) and the prediction from Maxent. This table was exported in ASCII format and used to develop various visualizations of niche patterns.

\section{Results}

We identified 12 Lutzomyia species in the Amaraji study during 2009, for a total of 1361 individuals across the 255 trap sites. Lutzomyia whitmani was by far the most abundant species, totaling 1195 individuals (87.8\%; Table 1). Other species recorded included L. evandroi (4.9\%), L. quinquefer (1.9\%), and L. complexa (1.3\%), among others.

In peridomiciliary environments, L. whitmani was even more dominant (98.2\% of individuals); L. evandroi, L. quinquefer, and L. migonei appeared to show a similar association with human-modified environments, albeit in much lower numbers. In contrast, L. complexa, L. tupynambai, L. sordelli, L. longispina, and L. walkeri appeared restricted to forest and forest edge in this study (Table 1). The concentration of $L$. whitmani in peridomiciliary environments was much greater than would be expected by chance $(P<0.05)$; tests for the remaining species were equivocal, probably owing to small sample sizes.

Table 1 shows the distribution of positive sites and individuals species in forested and peridomiciliary areas. Among the 120 sandfly positive sites, $82(68.3 \%)$ were in peridomiciliary areas, while $38(31.7 \%)$ were detected in forested areas $(P=0.005)$. L. whitmani and L. quinquefer were dominant in peridomestic sites $(P<0.05)$, as well as $L$. migonei $(P=0.07)$, while L. complexa, L. sordelli, and L. tupynambai were found almost exclusively in forested areas $(P<$ $0.05)$. For all other species, distribution of positive sites among peridomiciliary versus forested areas could not be determined $(P \gg 0.05)$. L. whitmani was the most abundant species as well as the most broadly distributed across the study area.

Relating patterns of occurrence to patterns of surface reflectance in the Landsat imagery, the jackknife process indicated NDVI from October and April as the environmental variables most associated with presence of $L$. whitmani. 
TABLE 2: Areas predicted as suitable for Lutzomyia whitmani by ecological niche model based on NDVI variables for combination of the east, west, and center regions of Amarají, Pernambuco, Brazil.

\begin{tabular}{|c|c|c|c|c|c|}
\hline & Regions & Ratio AUC* & Variables associated & $\begin{array}{c}\text { Partial ROC } \\
\mathrm{N}^{\circ} \text { ratio } \leq 1 \text { out of } 1000\end{array}$ & $Z$ statistics $(P)$ \\
\hline \multirow{4}{*}{ L. whitmani } & $\begin{array}{c}\text { East and Center } \\
\text { predict West }\end{array}$ & 1.06 & NDVI October & 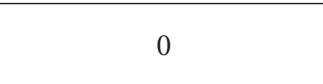 & $<0.0001$ \\
\hline & $\begin{array}{c}\text { West and Center } \\
\text { predict East }\end{array}$ & 1.12 & NDVI April & 0 & $<0.0001$ \\
\hline & $\begin{array}{l}\text { West and East } \\
\text { predict Center }\end{array}$ & 1.10 & NDVI October & 0 & 0.03 \\
\hline & Whole region of Amarají & & NDVI March & & - \\
\hline
\end{tabular}

* Area under the ROC curve, expressed as a ratio of observed AUC to the area under the curve of random expectations.

NDVI of March and August were omitted from models in light of their little contribution to fitness of models.

Niche models estimated from and projected among the three regions of the study area for which cloud-free imagery was available showed good (i.e., better than random expectances) coincidence with independent testing data sets (Table 2). In particular, for example, for L. whitmani, the model based on western and central regions predicted the distribution of the species in the eastern region with an AUC ratio mean of 1.12 , which has an associated probability value of $P<0.001$. The other two predictions were similarly statistically significantly better than random expectations (Table 2) thus amply confirming both the environmental influences on sandfly distribution and the predictive power of our models.

Figure 2 shows the relationship between modeled distributions in environmental space of L. whitmani as opposed to the other sandfly species at Amarají, revealing differences in the distribution of species according to the vegetation index. Figure 3 shows adding detail regarding presences detected for L. whitmani versus other species in forested and peridomiciliary environments. L. whitmani appears to be associated negatively with NDVI values (both in April, which is the rainy season, and in October, which is the dry season), as areas predicted as unsuitable for this species show generally higher NDVI values (Figures 2 and 3). Most other Lutzomyia species, on the other hand, appear associated positively with denser vegetation (i.e., higher NDVI values) in both seasons (Figures 3). Overall, then, Lutzomyia species' occurrences are associated with specific environmental combinations (with contrast among species) in Amarají.

\section{Discussion}

In the Amarají region as well as in other areas of Brazil, Lutzomyia whitmani has been implicated as the principal ACL vector, predominantly associated with Leishmania braziliensis, the main parasite species involved in transmission, although in southern region of the country it is considered only a secondary vector $[3,13]$. In Amarají, although 12 species were detected, L. whitmani was dominant constituting $87.8 \%$ overall of detections, and $95 \%$ in peridomiciliary locations. In forested areas, L. whitmani was less dominant (only $41.7 \%$ of detections), and other species played more meaningful roles in the sandfly community. This tie of $L$. whitmani to human-altered environments has been noted also in Amazon Basin, and in the center-west and southern parts of the country $[10,11,14]$.

However, in a nearby region of Pernambuco with greater forest cover, L. whitmani was found to be a relatively unimportant member of the sandfly community, and L. complexa and $L$. chot $i$ were much more numerous [33]. Among the other species detected at Amarají, L. evandroi and L. migonei both also appeared to be concentrated in peridomiciliary environments. Although far less common than L. whitmani, the human association of these species makes them of some interest in ACL transmission, as in other regions [11, 34, 35].

Given its domiciliation and massive dominance, $L$. whitmani is almost certainly the major ACL vector in the region $[24,36]$. While other species were rare around human habitations, this sand fly was more abundant in peridomiciliary and to a lesser degree forested areas, offering a possible vectorial role for other Leishmania species in the wooded environments. Detection of L. whitmani in peridomestic and forested areas reinforces the assumption that deforestation does not result in decline of the species habitat but adaptation and/or tolerance of different vegetation type and climatic condition.

Clearly, the next step in this process would be detailed analysis of (1) blood meal sources for each sandfly species in the region, (2) detection of Leishmania infections in the flies, and (3) identification and association of Leishmania strains in both sandflies and locally infected humans. This group of information, together with our spatial data, would offer significant insight into the details of ACL transmission cycle in the region.

Predictive models relating species occurrences to abiotic variables have been used in several previous studies of distribution and ecology of vectors, reservoirs, and infectious diseases [10, 21, 37]. Most previous analyzes have been carried out at scales that are set by resolution of the available environmental variables of occurrence data $[21,38,39]$. However, climate of the relatively small area designated in this study does not vary much over scales like this. Whereas the analysis of existing vegetation indirectly reflects the effects of rain and vegetation in the region, identifying ecologically disturbed and forested areas is of particular interest in the study of Lutzomyia spp. The amount of vegetation 


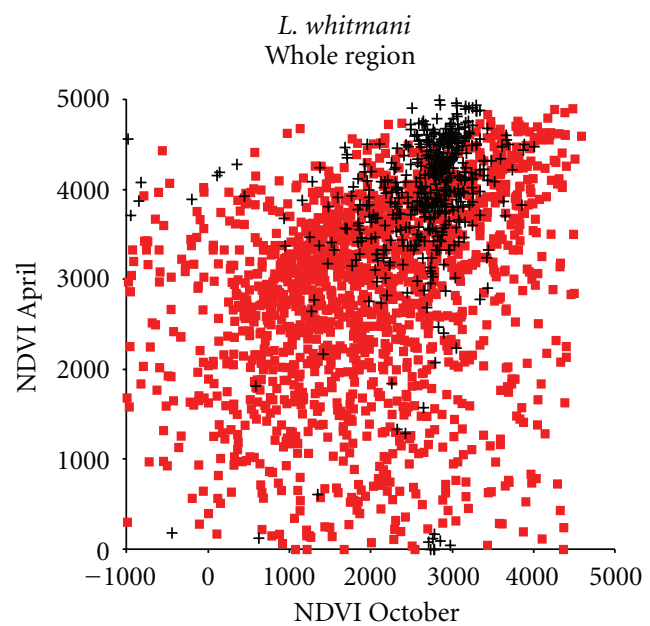

(a)

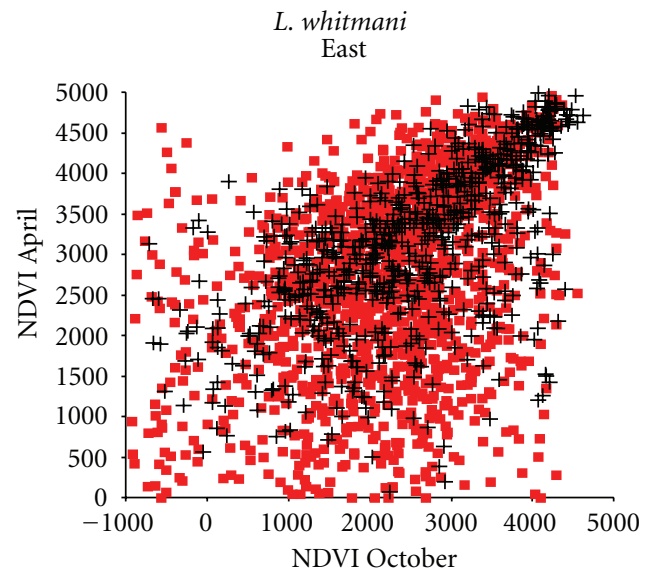

(c)

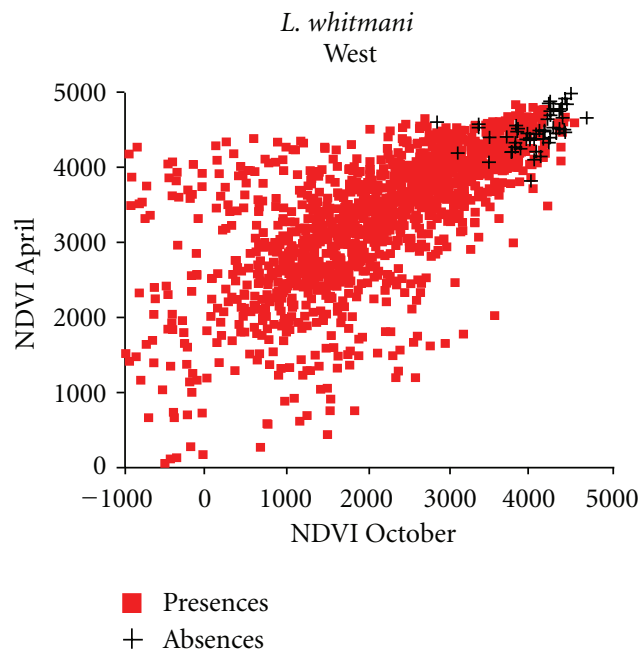

(e)

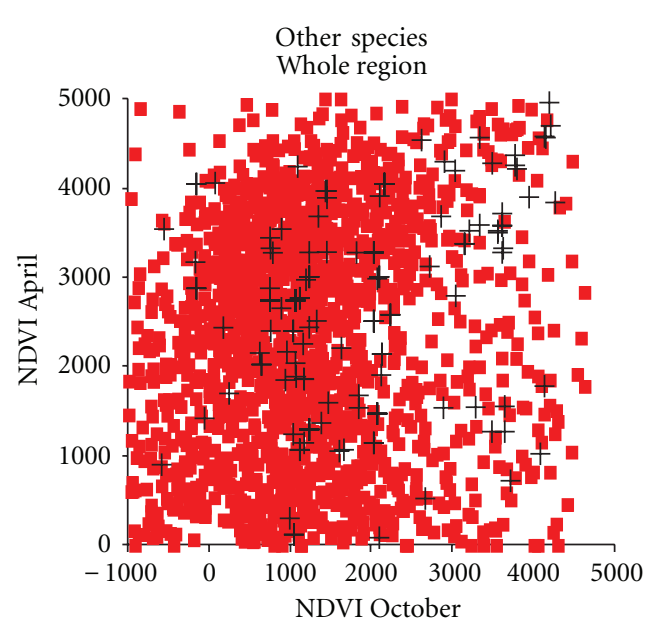

(b)

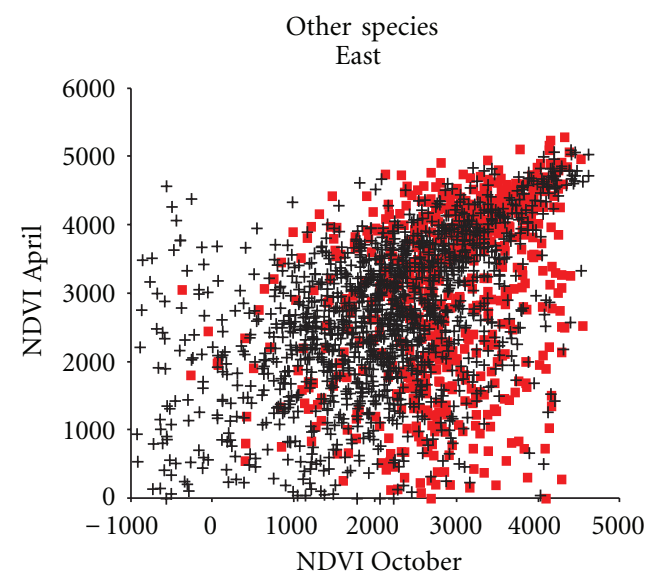

(d)

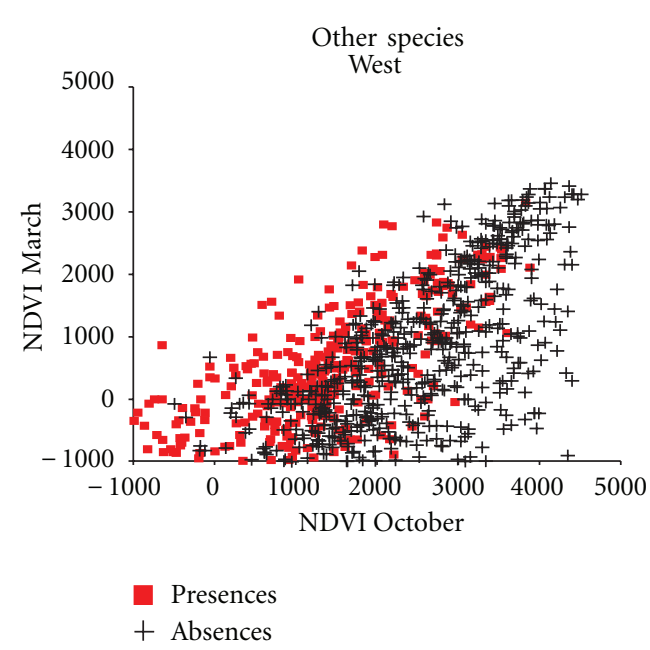

(f)

Figure 2: Presences and absences of Lutzomyia whitmani (a, c, e) and other species of Lutzomyia (b, d, f) in west, east, and center regions of the Amarají study area in Pernambuco, according to NDVI values October 2006 and March 2006. 


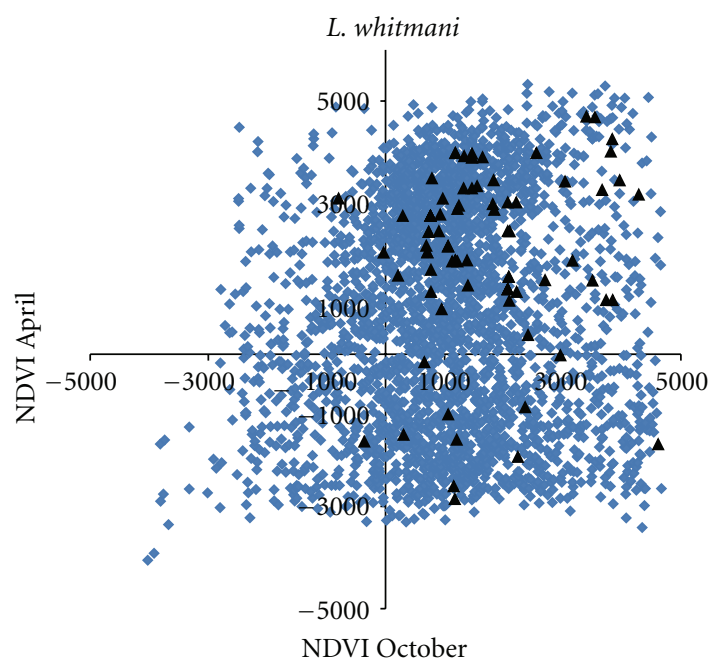

(a)

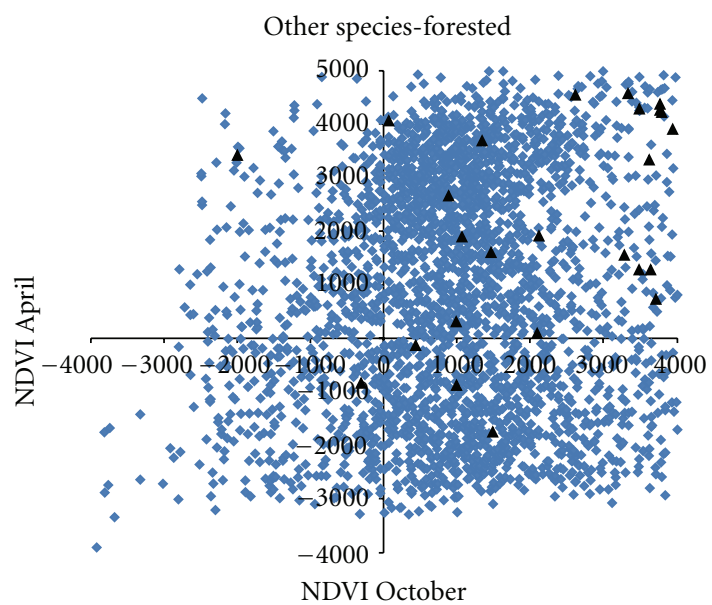

(b)

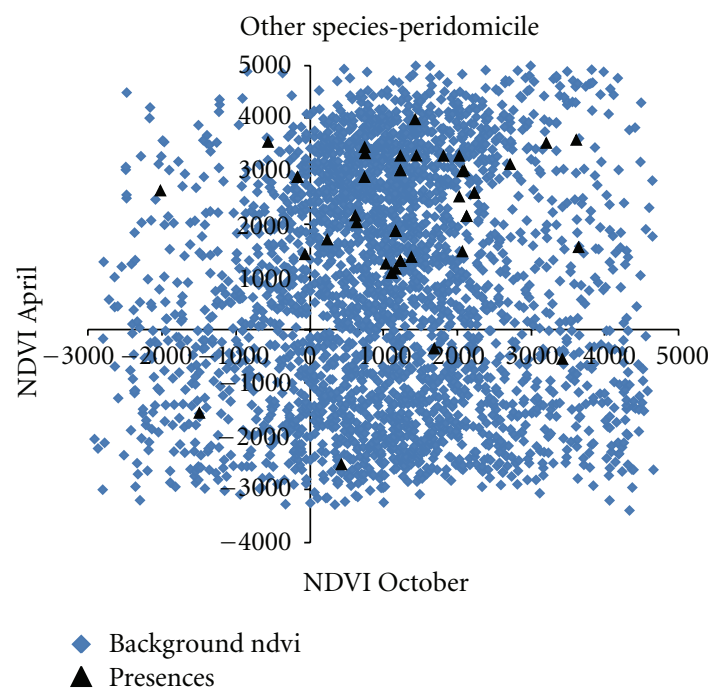

(c)

FIGURE 3: Summary of environmental characteristics of known occurrences (i.e., traps positive) for Lutzomyia whitmani versus two sets of other species (one of forested sites, one of peridomiciliary sites; see text for explanation). Occurrences shown as triangles are depicted against the background of conditions available across the study area (in gray). Environmental conditions of NDVI of October and April, Amarají, Pernambuco, Brazil, 2009.

in the dry and wet seasons were adequate in predictions of species occurrence, particularly for L. whitmani, which could be analyzed in detail. For this purpose, NDVI provides a good index of ecosystem function with strong correlation with absorbed photosynthetically active radiation [39].

In spite the fact that $L$. whitmani has been associated with geoecological factors, this highly anthropophilic species is also influenced by socioenvironmental changes and transformation on landscape $[10,34]$, which were not evaluated in this study.

There was a negative association between this species and higher NDVI values (denser vegetation), and predictions of the distribution of L. whitmani among regsions were statistically significantly better than random expectations. This result strongly suggests that it is feasible to predict the distribution of this important vector in regions where it is difficult to perform sampling due to factors such as difficult access and financial restrictions.

\section{References}

[1] Brasil-Ministério da Saúde, "Indicadores e Dados Básicostaxa de incidência da leishmaniose tegumentar americana," http://tabnet.datasus.gov.br/cgi/tabcgi.exe?idb2009/d0204 .def, 2009.

[2] G. Grimaldi-Junior and R. B. Tesh, "Leishmaniases of the New World: current concepts and implications for future research," Clinical Microbiology Reviews, vol. 6, no. 3, pp. 230-250, 1993.

[3] S. P. Brandão-Filho, D. Campbell-Lendrum, M. E. Brito, J. J. Shaw, and C. R. Davies, "Epidemiological surveys confirm an increasing burden of cutaneous leishmaniasis in north-east Brazil," Transactions of the Royal Society of Tropical Medicine and Hygiene, vol. 93, no. 5, pp. 488-494, 1999. 
[4] S. P. Brandão-Filho, F. G. Carvalho, M. E. F. Brito, F. A. Almei$\mathrm{da}$, and L. A. Nascimento, "American cutaneous leishmaniasis in Pernambuco, Brazil: eco-epidemiological aspects in "Zona da Mata" region," Memórias do Instituto Oswaldo Cruz, vol. 89, no. 3, pp. 445-449, 1994.

[5] S. Basano and L. M. A. Camargo, "Leishmaniose tegumentar americana: histórico, epidemiologia e perspectivas de controle," Revista Brasileira de Epidemiologia, vol. 7, pp. 328-337, 2004.

[6] J. E. Tolezano, "Ecoepidemiological aspects of American cutaneous leishmaniasis in the state of São Paulo, Brazil," Memórias do Instituto Oswaldo Cruz, vol. 89, no. 3, pp. 427-434, 1994.

[7] C. Alessi, E. A. B. Galati, J. R. Alves, and C. E. P. Corbett, "American cutaneous leishmaniasis in the Pontal of Paranapanema, SP, Brazil: ecological and entomological aspects," Revista do Instituto de Medicina Tropical de São Paulo, vol. 51, no. 5, pp. 277-282, 2009.

[8] A. C. Gomes, "Sand fly vectorial ecology in the State of São Paulo, Brazil," Memórias do Instituto Oswaldo Cruz, vol. 89, no. 3, pp. 457-460, 1994.

[9] F. Rangel, R. Lainson, A. A. Souza, P. Ready, and A. C. R. Azevedo, "Variation between geographical populations of Lutzomyia (Nyssomyia) whitmani (Antunes and Countinho, 1939) sensu lato (Diptera: Psychodidae: Phlebotominae) in Brazil," Memórias do Instituto Oswaldo Cruz, vol. 91, no. 1, pp. 43-50, 1996.

[10] P. Zeilhofer, O. P. Kummer, E. S. Santos, A. L. M. Ribeiro, and N. A. Missawa, "Spatial modeling of Lutzomyia (Nyssomyia) whitmani s.l. (Antunes \& Coutinho, 1939) (Diptera: Psychodidae: Phlebotominae) habitat suitability in the state of Mato Grosso, Brazil," Memórias do Instituto Oswaldo Cruz, vol. 103, no. 7, pp. 653-660, 2008.

[11] A. C. Gomes and E. A. B. Galati, "Ecological aspects of American cutaneous Leishmaniasis: 7-observations on the vectorial capacity of the sandfly in a primitive forest environment belonging to the Ribeira Valley region of the Serra do Mar system, S. Paulo State, Brazil," Revista de Saúde Pública, vol. 23, pp. 136-142, 1989 .

[12] N. A. Souza, C. A. Andrade-Coelho, M. L. Vilela, A. A. Peixoto, and E. F. Rangel, "Seasonality of Lutzomyia intermedia and Lutzomyia whitmani (Diptera: Psychodidae: Phlebotominae), occurring sympatrically in area of cutaneous leishmaniasis in the State of Rio de Janeiro, Brazil," Memórias do Instituto Oswaldo Cruz, vol. 97, no. 6, pp. 759-765, 2002.

[13] L. S. Rocha, A. Falqueto, C. B. Santos, J. Grimaldi, and E. Cupolillo, "Genetic structure of Lutzomyia (Nyssomyia) intermedia populations from two ecologic regions in Brazil where transmission of Leishmania (Viannia) braziliensis reflects distinct eco-epidemiologic features," American Journal of Tropical Medicine and Hygiene, vol. 76, no. 3, pp. 559-565, 2007.

[14] D. Dias-Lima, M. L. S. Guedes, and I. A. Sherlock, "Horizontal Stratification of the Sand Fly Fauna (Diptera: Psychodidae) in a Transitional Vegetation between Caatinga and Tropical Rain Forest, State of Bahia, Brazil," Memórias do Instituto Oswaldo Cruz, vol. 98, no. 6, pp. 733-737, 2003.

[15] S. Leonardo and J. M. M. Rebêlo, "A periurbanização de Lutzomyia whitmani em área de foco de leishmaniose cutânea, no Estado do Maranhão, Brasil," Revista da Sociedade Brasileira de Medicina Tropical, vol. 37, no. 3, pp. 282-284, 2004.

[16] S. P. Brandão-Filho, M. R. Donalisio, F. J. Silva et al., "Spatial and temporal patterns of Lutzomyia sand fly species occurrence in the Atlantic Forest region of Pernambuco, northeast Brazil," Journal of Vector Ecology, vol. 36, pp. 1-7, 2011.
[17] J. D. Andrade-Filho, M. B. Valente, W. A. Andrade, R. P. Brazil, and A. L. Falcão, "Flebotomíneos do estado de tocantins, Brasil (Diptera: Psychodidae)," Revista da Sociedade Brasileira de Medicina Tropical, vol. 34, no. 4, pp. 323-329, 2001.

[18] B. Galati, V. L. B. Nunes, M. E. C. Dorval et al., "Estudo dos flebotomíneos (Diptera, Pychodidae), em área de leishmaniose tegumentar, no Estado de Mato Grosso do Sul, Brasil," Revista de Saúde Pública, vol. 30, no. 2, pp. 115-128, 1996.

[19] N. A. Missawa, G. B. M. L. Maciel, and H. Rodrigues, "Distribuição geográfica de Lutzomyia (Nyssomyia) whitmani (Antunes \& Coutinho, 1939) no Estado de Mato Grosso," Revista da Sociedade Brasileira de Medicina Tropical, vol. 41, no. 4, pp. 369-373, 2008.

[20] T. Peterson and J. J. Shaw, "Lutzomyia vectors for cutaneous leishmaniasis in Southern Brazil: ecological niche models, predicted geographic distributions, and climate change effects," International Journal for Parasitology, vol. 33, no. 9, pp. 919931, 2003.

[21] L. F. Chaves, J. M. Cohen, M. Pascual, and M. L. Wilson, "Social exclusion modifies climate and deforestation impacts on a vector-borne disease," PLoS Neglected Tropical Diseases, vol. 2, no. 2, article e176, 2008.

[22] E. F. Rangel and R. Lainson, "Proven and putative vectors of American cutaneous leishmaniasis in Brazil: aspects of their biology and vectorial competence," Memórias do Instituto Oswaldo Cruz, vol. 104, no. 7, pp. 937-954, 2009.

[23] S. P. Brandão-Filho, M. E. Brito, F. G. Carvalho et al., "Wild and synanthropic hosts of Leishmania (Viannia) braziliensis in the endemic cutaneous leishmaniasis locality of Amarají, Pernambuco State, Brazil," Transactions of the Royal Society of Tropical Medicine and Hygiene, vol. 97, no. 3, pp. 291-296, 2003.

[24] M. E. F. Brito, M. S. Andrade, M. G. Mendonça et al., "Species diversity of Leishmania (Viannia) parasites circulating in an endemic area for cutaneous leishmaniasis located in the Atlantic rainforest region of northeastern Brazil," Tropical Medicine and International Health, vol. 14, no. 10, pp. 1278-1286, 2009.

[25] J. R. McNelly, "The CDC trap as a special monitoring tool," in Proceedings of the 76 Annual Meeting of the New Jersey Mosquito Control Association, pp. 26-33.

[26] D. G. Young and M. A. Duncan, "Guide to the identification and geographic distribution of Lutzomyia sandflies in Mexico, the West Indies, Central and South America (Diptera:Psychodidae)," Memoirs of the American Entomological Institute, vol. 54, pp. 1-881, 1994.

[27] S. J. Phillips, R. P. Anderson, and R. E. Schapire, "Maximum entropy modeling of species geographic distributions," Ecological Modelling, vol. 190, no. 3-4, pp. 231-259, 2006.

[28] A. T. Peterson and K. P. Cohoon, "Sensitivity of distributional prediction algorithms to geographic data completeness," Ecological Modelling, vol. 117, no. 1, pp. 159-164, 1999.

[29] R. G. Pearson, W. Thuiller, M. B. Araújo et al., "Model-based uncertainty in species range prediction," Journal of Biogeography, vol. 33, no. 10, pp. 1704-1711, 2006.

[30] A. T. Peterson, M. Papes, and J. Soberón, "Rethinking receiver operating characteristic analysis applications in ecological niche modeling," Ecological Modelling, vol. 213, no. 1, pp. 6372, 2008.

[31] H. Fielding and J. F. Bell, "A review of methods for the assessment of prediction errors in conservation presence/absence models," Environmental Conservation, vol. 24, no. 1, pp. 3849, 1997. 
[32] J. M. Lobo, A. Jimenez-Valverde, and R. Real, "AUC: a misleading measure of the performance of predictive distribution models," Global Ecology and Biogeography, vol. 17, no. 2, pp. 145-151, 2008.

[33] M. S. Andrade, H. F. Valença, A. L. da Silva et al., "Sandfly fauna in a military training area endemic for American tegumentary leishmaniasis in the Atlantic Rain Forest region of Pernambuco, Brazil," Cadernos de Saúde Pública, vol. 21, no. 6, pp. 1761-1767, 2005.

[34] M. F. F. M. Ximenes, V. P. M. E Silva, V. S. Q. Paula et al., "Phlebotomine (Diptera: Psychodidae) and leishmaniasis in Rio Grande do Norte State Brazil: anthropic environment responses," Neotropical Entomology, vol. 36, no. 1, pp. 128-137, 2007.

[35] D. H. Campbell-Lendrum, M. C. Pinto, S. P. Brandão-Filho, A. A. Souza, P. D. Ready, and C. R. Davies, "Experimental comparison of anthropophily between geographically dispersed populations of Lutzomyia whitmani (Diptera: Psychodidae)," Medical and Veterinary Entomology, vol. 13, no. 3, pp. 299-309, 1999.

[36] J. Soberón and A. T. Peterson, "Interpretation of models of fundamental ecological niches and species' distributional areas," Biodiversity Informatics, vol. 2, pp. 1-10, 2005.

[37] R. A. Williams, F. O. Fasina, and A. T. Peterson, "Predictable ecology and geography of avian influenza (H5N1) transmission in Nigeria and West Africa," Transactions of the Royal Society of Tropical Medicine and Hygiene, vol. 102, no. 5, pp. 471479, 2008.

[38] A. T. Peterson, R. R. Lash, D. S. Carroll, and K. M. Johnson, "Geographic potential for outbreaks of Marburg hemorrhagic fever," American Journal of Tropical Medicine and Hygiene, vol. 75, no. 1, pp. 9-15, 2006.

[39] J. T. Kerr and M. Ostrovsky, "From space to species: ecological applications for remote sensing," Trends in Ecology and Evolution, vol. 18, no. 6, pp. 299-305, 2003. 


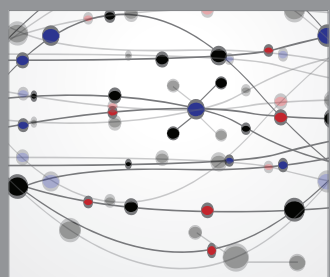

The Scientific World Journal
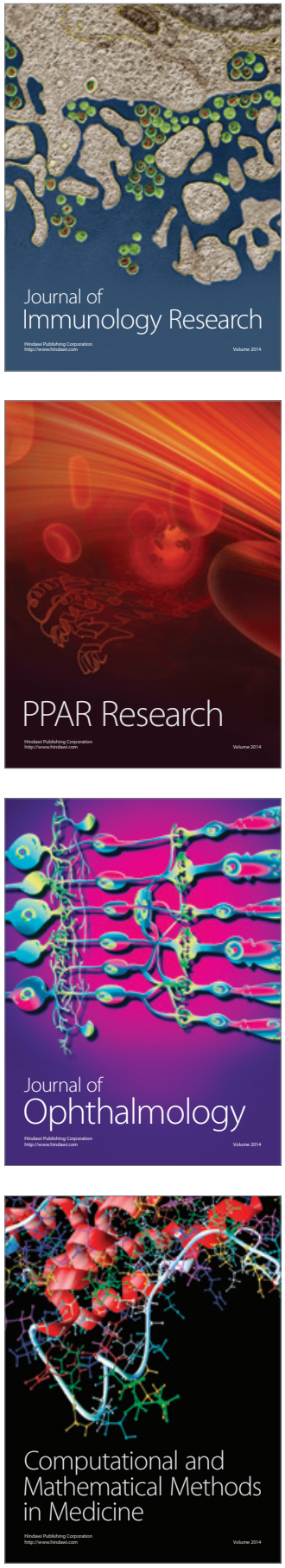

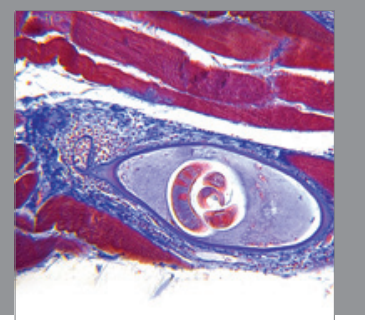

Gastroenterology

Research and Practice
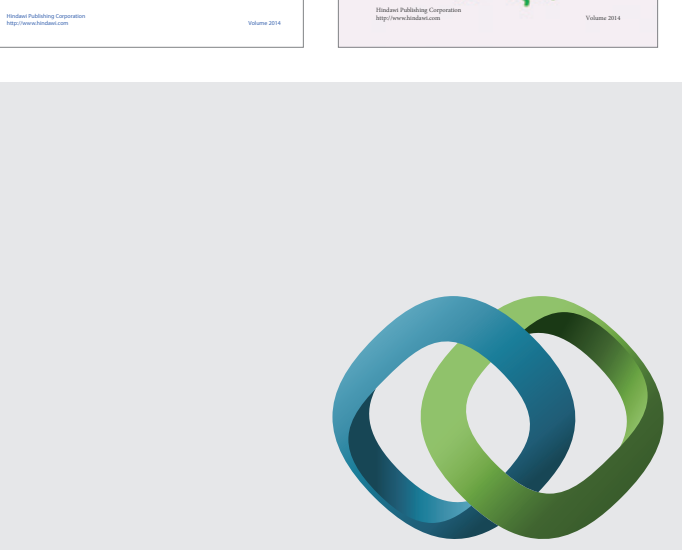

\section{Hindawi}

Submit your manuscripts at

http://www.hindawi.com
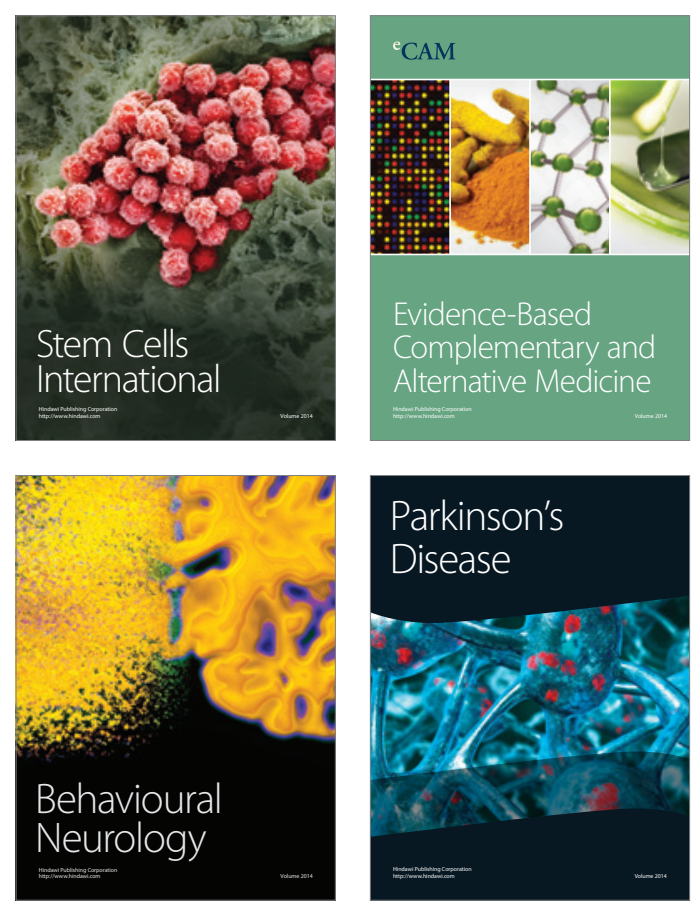

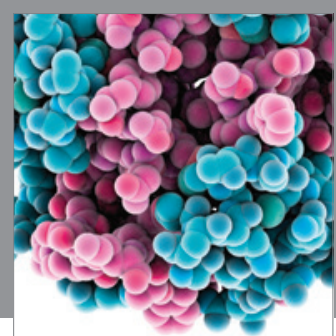

Journal of
Diabetes Research

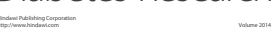

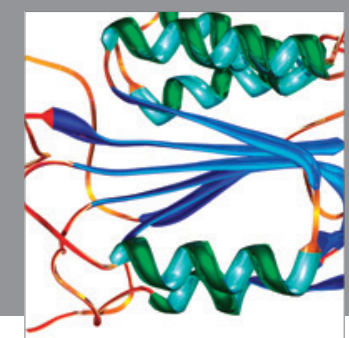

Disease Markers
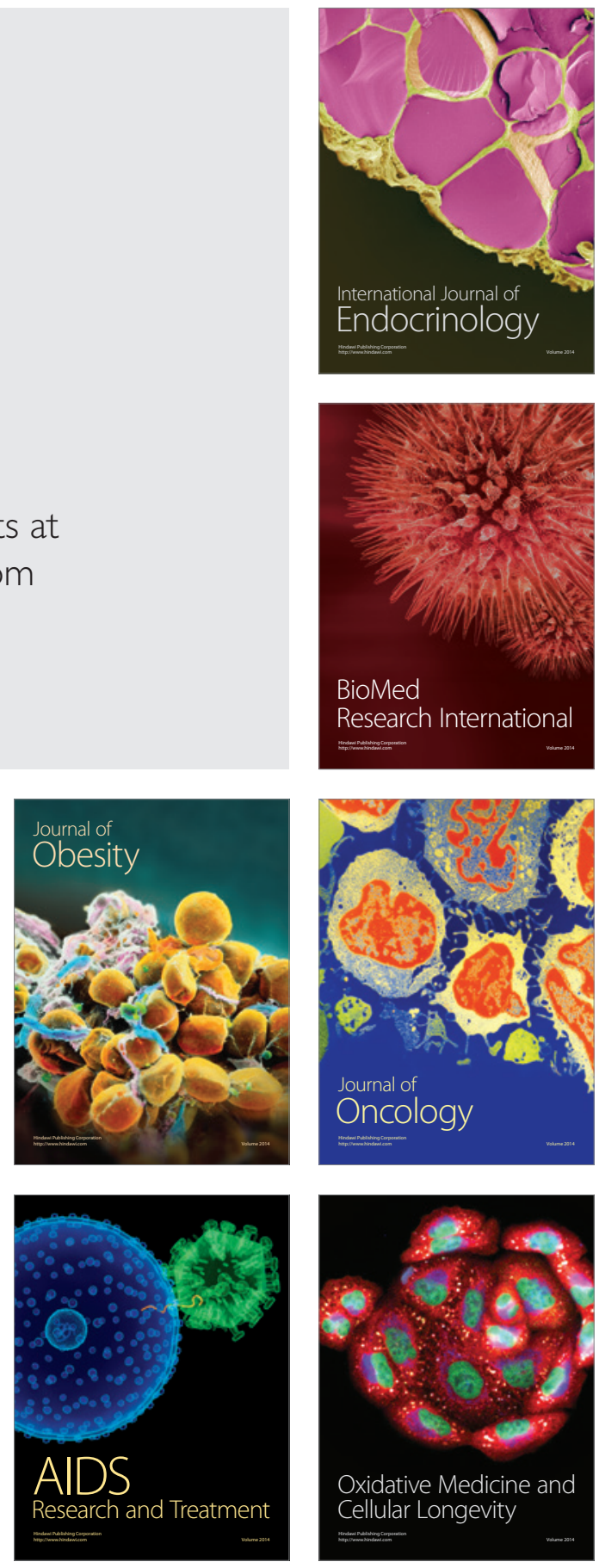